\title{
Intracranial pressure following decompressive hemicraniectomy for malignant cerebral infarction: clinical and treatment correlations
}

\author{
Monitorização da pressão intracraniana em pacientes tratados com hemicraniectomia \\ descompressiva por acidente vascular cerebral maligno de artéria cerebral média: \\ correlações clínicas e terapêuticas \\ Bruno Ferreira Funchal', Maramélia Miranda Alves', Italo C. Suriano', Feres Eduardo Chaddad-Neto', Maria \\ E. M. R. Ferraz', Gisele Sampaio Silva ${ }^{1,2}$
}

\begin{abstract}
Decompressive craniectomy (DC) reduces mortality and improves outcome in patients with massive brain infarctions. The role of intracranial pressure (ICP) monitoring following DC for stroke has not been well established. Methods: We evaluated 14 patients admitted to a tertiary hospital with malignant middle cerebral artery infarctions, from October 2010 to February 2015, who underwent DC and had ICP monitoring. Patients with and without episodes of ICP elevation were compared. Results: Fourteen patients were submitted to DC and had ICP monitoring following the procedure during the period. Ten patients $(71.4 \%)$ had at least one episode of sustained elevated ICP in the first seven days after surgery. Maximal ICP levels had no correlation with age, time to hemicraniectomy or Glasgow Coma Scores at admission, but had a trend toward correlation with the National Institutes of Health Stroke Scale score at admission $(p=$ 0.1). Ventriculitis occurred in $21.4 \%$ of the patients. Conclusions: High ICP episodes and ventriculitis were common in patients following hemicraniectomy for malignant middle cerebral artery strokes. Therefore, the implications of ICP and benefits of the procedure should be firmly established.
\end{abstract}

Keywords: cerebral infarction; decompressive craniectomy; intracranial pressure.

\section{RESUMO}

Craniectomia descompressiva (CD) reduz a mortalidade e melhora o desfecho em pacientes com infartos malignos de artéria cerebral média (ACM). O papel da monitorização da pressão intracraniana (PIC) após CD para infartos malignos de ACM não está bem estabelecido. Métodos: Avaliamos pacientes consecutivos internados em um hospital terciário com infartos malignos de ACM de outubro/2010 a fevereiro/2015 tratados com CD e submetidos à monitorização da PIC. Foram comparados pacientes com e sem episódios de elevação de PIC. Resultados: Quatorze pacientes (idade média 49,0 \pm 12,4 anos, 42,9\% do sexo masculino) foram avaliados. Dez pacientes $(71,4 \%)$ tiveram pelo menos um episódio de elevação da PIC nos primeiros sete dias após a cirurgia. A PIC máxima média foi de 26,71 $\pm 11,64 \mathrm{mmHg}$. Os níveis máximos de PIC não apresentaram correlação com a idade, o tempo de hemicraniectomia ou com a pontuação na Escala de Coma de Glasgow na admissão, mas houve tendência a ser correlacionada com a pontuação da National Institutes of Health Stroke Scale na admissão ( $p=0,1)$. Ventriculite ocorreu em 21,4\% dos pacientes. Conclusões: Os episódios de aumento da PIC foram comuns em pacientes tratados com CD por infarto maligno de MCA e ventriculite foi evento adverso frequente nesses pacientes. Portanto, as implicações da monitorização da PIC sobre o resultado funcional, bem como os riscos e benefícios do procedimento, devem ser melhor estabelecidos.

Palavras-chave: infarto cerebral; craniectomia descompressiva; hipertensão intracraniana.

Stroke is the second leading cause of mortality worldwide and the leading cause of disability ${ }^{1}$. A particularly severe form of ischemic stroke, caused by the interruption of blood flow in the proximal portion of the middle cerebral artery
(MCA) or the internal carotid artery known as malignant MCA infarction or malignant MCA syndrome, has a mortality rate of about $70 \%$ to $80 \%$ with optimized clinical treatment ${ }^{2}$. The decline in cerebral blood flow causes the failure of the

\footnotetext{
${ }^{1}$ Universidade Federal de São Paulo, Departamento de Neurologia e Neurocirurgia, São Paulo SP, Brasil;

${ }^{2}$ Hospital Israelita Albert Einstein, Programa Integrado de Neurologia and Instituto de Ensino e Pesquisa, São Paulo SP, Brasil.

Correspondence: Bruno Ferreira Funchal; Rua Leandro Dupret, 662 / 203; 04025-013 São Paulo SP, Brasil; E-mail: dr.funchal@hotmail.com

Conflict of interest: There is no conflict of interest to declare.

Received 11 October 2017; Received in final form 31 July 2018; Accepted 27 August 2018.
} 
sodium-potassium pump, the breakdown of the blood-brain barrier, cytotoxic edema and, consequently, cell death. This cascade of events when present in large brain volume leads to rapid neurologic deterioration due to cerebral edema with a significant mass effect, herniation of brain structures and compression of the brainstem ${ }^{3}$. The incidence of this syndrome is estimated to be $10-20 / 100,000$ individuals, about $10 \%$ of all hemispheric strokes.

Patients with malignant MCA syndrome are, on average, 10 years younger than the overall group of patients with ischemic stroke ${ }^{3}$. Decompressive craniectomy (DC) is a therapeutic option capable of saving lives and reducing disability in patients with malignant MCA syndrome. However, around $20 \%$ of the patients treated with DC still die despite treatment ${ }^{4,5,6}$. It is possible that intracranial hypertension plays a role in the clinical deterioration and death of such patients. The behavior of intracranial pressure (ICP) after DC, as well as the correlation between increased ICP after surgery, with clinical characteristics and prognosis, are not clear in the literature. The objective of our observational, retrospective study was to describe a series of patients with malignant MCA stroke treated with DC and monitored with ICP monitors, with a focus on ICP behavior after surgery and its impact upon treatment and outcomes.

\section{METHODS}

We evaluated 16 consecutive patients admitted to a tertiary hospital with malignant MCA infarctions from October 2010 to February 2015, of whom 14 underwent DC and had ICP monitoring, and are the focus of this study. Patients were identified through an active search of paper and electronic medical records from our neurological intensive care unit (ICU), emergency department and operating room registries. Malignant MCA syndrome was defined as infarction of an area larger than $50 \%$ of the MCA with a decreased level of consciousness on the National Institutes of Health Stroke Scale (NIHSS) (score of 1 or greater on NIHSS 1a). Exclusion criteria were the presence of hemorrhagic transformation and contralateral ischemia. We evaluated demographic characteristics, the frequency of stroke risk factors, the Glasgow Coma Scale (GCS) and NIHSS scores on admission and presurgical evaluation, the clinical status on the presurgical examination, neuroimaging findings, time from initial symptoms and from hospital arrival to DC, the maximal values of ICP registered for the first week, treatments administered for sustained increased ICP (hyperosmolar therapy), the frequency of clinical complications ( fever, pneumonia, hyponatremia and ventriculitis), length of hospital and intensive care unit stay and the modified Rankin Scores (mRS) at discharge and at six months. The ICP was monitored using an external ventricular drainage with a continuous ICP reading via a fiber optic monitor in all patients. An external ventricular drain transducer was leveled to the patient's external auditory meatus. Hyperosmolar therapy in our service consists of the use of either mannitol $20 \%(1 \mathrm{mg} / \mathrm{kg})$ or $20 \mathrm{~mL}$ of $20 \%$ hypertonic saline. Sustained intracranial hypertension was defined as an ICP greater than $20 \mathrm{mmHg}$ that persisted for five minutes or longer. After elevated ICP detection, the following measures were undertaken in this specific order by our local protocol for the treatment of intracranial hypertension: the bed was placed at an angle of 30 degrees, sedation, cerebrospinal fluid drainage, hyperosmolar therapy and, finally, barbiturate coma. Hyperosmolar therapy was given every six hours if the ICP persisted in its elevation despite follow-up measures and if sodium levels were no more than $160 \mathrm{mEq} / \mathrm{L}$. Ventriculitis was defined by a positive cerebrospinal fluid culture. This study was submitted to and approved by the Ethics Committee of UNIFESP - EPM.

\section{Statistical analysis}

A descriptive analysis (including mean, standard deviation, median and interquartile interval) was used to describe the characteristics of the patients. The t-test for independent samples or the Mann-Whitney test was used to compare continuous variables. Categorical variables were compared using the chi-square test or Fisher's exact test. The correlation between the ICP values and continuous variables was assessed by Pearson's or Spearman's correlation, as indicated. We considered probability values less than 5\% $(\mathrm{p}<0.05)$ as statistically significant. Statistical studies were performed using the SPSS 17 software, IBM, Chicago, IL.

\section{RESULTS}

A total of 16 patients were treated with DC for malignant MCA stroke in the study period. Of these patients, 14 had an ICP monitor placed, which is a common practice in the service, and were therefore included in our study (mean age $49.0 \pm 12.4$ years old, $42.9 \%$ males). Hypertension, diabetes, and dyslipidemia were seen in $50 \%, 14.3 \%$ and $35.7 \%$ of the patients, respectively. Four patients $(28.6 \%)$ had a personal history of a previous stroke. The right and left hemispheres were equally affected. A hyperdense MCA sign was seen in six patients (42.9\%). A total of three patients $(21.4 \%)$ were treated with thrombolysis. Most of the patients had a cardioembolic stroke (50\%), followed by other causes $(21.4 \%)$ and cryptogenic stroke $(28.6 \%)$.

Decompressive craniectomy with duroplasty was performed in all patients without ischemic tissue resection, and an external ventricular drain with ICP monitoring was used in all patients. Table 1 shows the patients' demographic and clinical characteristics. The median GCS at admission and on immediate presurgical evaluation was $11[8,14]$. The median NIHSS score at admission was 17 [13, 21.5], while the median presurgical scores were 18 [15.2, 20.0]. Five patients 
Table 1. Baseline characteristics of patients.

\begin{tabular}{lc}
\hline Characteristics & Values \\
\hline Age, years & $49.0 \pm 12.4$ \\
\hline Males & $42.9 \%$ \\
\hline Hypertension & $50.0 \%$, \\
\hline Diabetes & $14.3 \%$ \\
\hline Dyslipidemia & $35.7 \%$ \\
\hline $\begin{array}{l}\text { Systolic blood pressure at admission } \\
\text { (mmHg) }\end{array}$ & $135 \pm 20.3$ \\
\hline $\begin{array}{l}\text { Diastolic blood pressure at admission } \\
\text { (mmHg) }\end{array}$ & $84.2 \pm 14.0$ \\
\hline Heart rate at admission (bpm) & $83.0 \pm 13.2$ \\
\hline Hyperdense MCA sign & $42.9 \%$ \\
\hline Treatment with thrombolysis & $21.4 \%$ \\
\hline TOAST classification & \\
\hline Cardioembolic stroke & $50 \%$ \\
\hline Other causes & $21.4 \%$ \\
\hline Cryptogenic stroke & $28.6 \%$ \\
\hline MCA: middle cerebral artery; TOAST: Trial of Org 10172 in Acute Stroke \\
Treatment
\end{tabular}

(35.7\%) presented with anisocoria on presurgical evaluation. The median time from hospital admission to DC was $20.9 \pm 13.3$ hours. The most frequent complications during the ICU stay were epileptic crises $(28.6 \%)$ and pneumonia $(57.1 \%)$. Thirteen patients $(92.9 \%)$ were treated with antibiotics during their hospital stay (Table 2). Ten patients (71.4\%) had at least one episode of sustained, elevated ICP in the first seven days after surgery. The mean maximal ICP was $26.71 \pm 11.64 \mathrm{mmHg}$. Half of the patients received at least one dose of hyperosmolar treatment during their ICU stay. All patients with anisocoria before the procedure had at least one episode of ICP elevation versus $55.6 \%$ of the patients without anisocoria $(\mathrm{p}=0.07)$. The mean maximal ICP achieved was $29.17 \pm 12.62 \mathrm{mmHg}$ in those who were febrile in the first 48 hours after the procedure versus 24.88 $\pm 11.35 \mathrm{mmHg}$ in those who were not $(\mathrm{p}=0.5)$. Patients who died during hospitalization had a mean maximal ICP of 31.0 $\pm 25.4 \mathrm{mmHg}$ versus $26.0 \pm 9.8 \mathrm{mmHg}$ in those who were discharged home $(p=0.6)$. Maximal ICP levels had no correlation with age, time to hemicraniectomy GCS at admission, but had a trend toward correlation with NIHSS scores at admission $(p=0.1)$. Ventriculitis occurred in $21.4 \%$ of the patients. All patients who had ventriculitis had at least one episode of elevated ICP versus $63.6 \%$ of the patients without ventriculitis $(p=0.2)$. The mean length of hospital stay was $39.5 \pm 25.1$ days, with a mean of $19.3 \pm 7.7$ days in the ICU. Two patients $(14.3 \%)$ died during their hospital stay, 11 patients had an mRS of $5(78.6 \%)$ and only one patient had an mRS of 4 at hospital discharge. Only six patients had a follow-up medical appointment after six months, of whom $50 \%$ had an
Table 2. Stroke management, complications, and prognosis.

\begin{tabular}{lc}
\hline Characteristics & Values \\
\hline GCS at admission & $11[8,14]$ \\
\hline NIHSS score at admission & $17[13,21.5]$ \\
\hline Presurgical NIHSS score & $18[15.2,20.0]$ \\
\hline Anisocoria on presurgical evaluation & $35.7 \%$ \\
\hline Time from hospital admission to DC (hours) & $20.9 \pm 13.3$ \\
\hline Epileptic crises & $28.6 \%$ \\
\hline Pneumonia & $57.1 \%$ \\
\hline Ventriculitis & $21.4 \%$ \\
\hline Mean maximal ICP (mmHg) & $26.7 \pm 11.6$ \\
\hline Hospital length of stay (days) & $39.5 \pm 25.1$ \\
\hline ICU length of stay (days) & $19.3 \pm 7.7$ \\
\hline Modified Rankin Scale at discharge & \\
\hline 4 & $7.1 \%$ \\
\hline 5 & $78.6 \%$ \\
\hline 6 & $14.3 \%$ \\
\hline Modified Rankin Scale at 6 months & \\
\hline 1 & $16.6 \%$ \\
\hline 4 & $33.3 \%$ \\
\hline 6 & $50 \%$ \\
\hline
\end{tabular}

GCS: Glasgow coma scale; NIHSS: National Institutes of Health Stroke Scale; DC: decompressive craniectomy; ICP: intracranial pressure; ICU: intensive care unit.

$\mathrm{mRS} \leq 4$. The mortality rate was $14.3 \%$ during the hospital stay and $50 \%$ within six months.

\section{DISCUSSION}

Postoperative ICP monitoring in patients with malignant MCA stroke showed a high frequency of intracranial hypertension episodes despite the DC. We found a possible association between the presence of intracranial hypertension and clinical variables such as the presence of anisocoria preceding surgery, ventriculitis, and NIHSS scores on admission. The frequency of ventriculitis associated with the use of an ICP catheter was high. Although elevated ICP was correlated with higher presurgery mortality in patients with malignant MCA syndrome, the role of ICP monitoring following DC for stroke has rarely been evaluated. In a retrospective series of 12 patients, elevated ICP commonly occurred following DC for stroke, and ICP monitoring influenced postoperative management with standard measures for ICP lowering being used frequently ${ }^{7}$. In our series, $71.4 \%$ of the patients had at least one episode of high ICP during the first week after DC and half of them received at least one dose of hyperosmolar treatment (either mannitol or hypertonic saline) during their ICU stay, suggesting that ICP values did influence the treatment in our patients as well. 
Few earlier studies have discussed the role of ICP monitoring after DC for malignant MCA stroke. In a series evaluating ICP after DC for malignant MCA stroke and traumatic brain injury, ICP values significantly distinguished between favorable and unfavorable outcomes and predicted 30-day mortality ${ }^{8}$.

In another series of 25 patients, elevated ICP after DC for malignant MCA stroke was associated with mortality at six months ${ }^{9}$. There was a possible correlation between higher NIHSS scores at admission, anisocoria and ventriculitis and higher ICP in our series. The NIHSS scores reflect the burden of ischemic lesion; therefore, it is expected that patients with higher lesion volumes more frequently present with episodes of increased ICP. Additionally, anisocoria is a surrogate marker for transtentorial brain herniation. Although previous studies have shown that, in patients with malignant MCA syndrome, pupillary abnormalities and severe brainstem compression may be present despite normal ICP values, patients treated with DC who were already showing pupillary dilatation probably have more encephalic tissue shifts than patients treated without anisocoria and possibly higher ICP.

Ventriculitis was common in our patients. A series, published in $2015^{7}$, that assessed ICP after DC in patients with malignant MCA stroke, showed no complications related to the procedure. In this series ${ }^{7}$, however, all patients received ICP catheters impregnated with antibiotics, which may explain in part the difference in infection rates between that study and our series.

Our study has some limitations. This was a retrospective, observational study with a small number of patients and no neuroimaging follow-up data. Therefore, the evaluation of the relationship between elevated ICP after DC and clinical outcomes was not possible. The loss of outpatient follow-up after discharge restricted the analysis of clinical outcomes in the long term. Additionally, the absence of a control group precluded comparison of outcome in patients with and without ICP monitoring. However, data regarding ICP after DC for large hemispheric infarctions and its influence upon prognosis are scarce; therefore, our study can be hypothesis generating and raise the question of the importance of ICP monitoring in these patients.

In conclusion, high ICP episodes were common in patients following hemicraniectomy for malignant MCA strokes. The implications of ICP monitoring upon functional outcome, as well as the risks and benefits of the procedure, should be better established.

\section{References}

1. Mozaffarian D, Benjamin EJ, Go AS, Arnett DK, Blaha

MJ, Cushman M et al. Heart disease and stroke

statistics - 2015 update: a report from the American

Heart Association. Circulation. 2015 Jan;131(4):e29-322.

https://doi.org/10.1161/CIR.0000000000000152

2. Hacke W, Schwab S, Horn M, Spranger M, De Georgia M, Kummer R. 'Malignant' middle cerebral artery territory infarction: clinical course and prognostic signs. Arch Neurol. 1996 Apr;53(4):309-15. https://doi.org/10.1001/archneur.1996.00550040037012

3. Mohr JP, Wolf PA, Grotta JC,. Moskowitz MA, Mayberg M, Kummer RStroke: pathophysiology, diagnosis, and management. $5 \mathrm{a}$ ed. Philadelphia, PA: Saunders; 2011. Vol. 1.

4. Jüttler E, Schwab S, Schmiedek P, Unterberg A, Hennerici M, WoitzikJ. Decompressive surgery for the treatment of malignant infarction of the middle cerebral artery (DESTINY): a randomized, controlled trial. Stroke. 2007 Sep;38(9):2518-25. https://doi.org/10.1161/STROKEAHA.107.485649

5. Vahedi K, Vicaut E, Mateo J, Kurtz A, Orabi M, Guichard JP, et al. Sequential-design, multicenter, randomized, controlled trial of early decompressive craniectomy in malignant middle cerebral artery infarction (DECIMAL Trial). Stroke. 2007 Sep:38(9):2506-17. https://doi.org/10.1161/STROKEAHA.107.485235

6. Hofmeijer J, Kappelle LJ, Algra A, Amelink GJ, van Gijn J, Worp HB Surgical decompression for space-occupying cerebral infarction (the Hemicraniectomy After Middle Cerebral Artery infarction with Life-threatening Edema Trial [HAMLET]): a multicentre, open, randomised trial. Lancet Neurol. 2009 Apr;8(4):326-33. https://doi.org/10.1016/S1474-4422(09)70047-X

7. Paldor I, Rosenthal G, Cohen JE, Leker R, Harnof S, Shoshan Y et al. Intracranial pressure monitoring following decompressive hemicraniectomy for malignant cerebral infarction. J Clin Neurosci. 2015 Jan;22(1):79-82. https://doi.org/10.1016/j.jocn.2014.07.006

8. Sauvigny T, Göttsche J, Czorlich P, Vettorazzi E, Westphal M, Regelsberger J. Intracranial pressure in patients undergoing decompressive craniectomy: new perspective on thresholds. J Neurosurg. 2018 Mar;128(3):819-27. https://doi.org/10.3171/2016.11.JNS162263

9. Jeon SB, Park JC, Kwon SU, Kim YJ, Lee S, Kang DW et al. Intracranial Pressure Soon After Hemicraniectomy in Malignant Middle Cerebral Artery Infarction. J Intensive Care Med. 2018 May;33(5):310-6. https://doi.org/10.1177/0885066616675598 